https://doi.org/10.4314/ijs.v22i1.12

Ife Journal of Science vol. 22, no. 1 (2020)

\title{
ASSESSMENT OF LAGOS SOILS FOR SOME PERSISTENT ORGANIC POLLUTANTS
}

\author{
*Alani, R., Olayinka, K. and Alo, B. \\ Chemistry Department, University of Lagos, Akoka, Lagos, Nigeria. Email addresses: AB-profjidealo@yahoo.com, \\ Tel.:2348022903841; OK-keolayi20002000@yahoo.com, Tel.: 2348023204841; and AR- ralani@unilag.edu.ng, Tel.: \\ 2348025213236. *Author for correspondence
}

(Received: 20 ${ }^{\text {th }}$ November, 2019; Accepted: $21^{\text {st }}$ March, 2020)

\section{ABSTRACT}

\begin{abstract}
Contamination of Lagos soils with persistent, bioaccumulative and toxic micropollutants (PBTs) may not only affect the non-target species residing in the soil, but also raises the concern of the possibility of the chemicals finding their way into the Lagoon and other water courses via soil run-off and leaching. In this study, soil samples were collected from three busy areas of Lagos (Apapa, Okobaba and Iddo) and analyzed for Polychlorinated Biphenyls (PCBs), Organochlorine pesticides (OCS), and Polycyclic Aromatic Hydrocarbons (PAHs). Gas Chromatography with Mass Selective Detector (GC/MSD) was used for the analyses. Iddo had the highest percentage organic carbon content of $39.39 \%$ with highest total PAHs of $2,706.93 \mathrm{ng} / \mathrm{g}$. The highest total PCBs of $23.63 \mathrm{ng} / \mathrm{g}$ was found at Apapa 3 which was one of the three sampling points in Apapa. PCB 74 was the only PCB found in all the soil samples and ranged between $3.55 \mathrm{ng} / \mathrm{g}$ and $23.64 \mathrm{ng} / \mathrm{g}$ at Apapa 1 and Apapa 2 respectively. High concentrations of the following organic compounds were also obtained at the following locations- naphthalene $(1,625.10 \mathrm{ng} / \mathrm{g})$ at Iddo; dichlorodiphenyldichloroethylene (p,p'DDE), (117.98 ng/g) at Okobaba, and PCB $74(23.63 \mathrm{ng} / \mathrm{g})$ at Apapa 1. The results obtained showed that the higher the municipal activity, the higher the percentage organic carbon content.
\end{abstract}

Key words: Bioaccumulative and toxic micropollutants, Gas chromatography/Mass selective detector, Persistent organic carbon, Soil organic pollutants

\section{INTRODUCTION}

Management of Persistent Bioaccumulative and Toxic organic micro-pollutants (PBTs) such as Polychlorinated Biphenyls (PCBs), Organochlorine pesticides (OCs), and Polycyclic Aromatic Hydrocarbons (PAHs), have become serious issues in Nigeria (Edwards, 1983). This is due to the fact that, attention has not been paid to the inventory of chemicals and chemical wastes in the country until of recent, though the use of the chemicals in Nigeria for agriculture, health and other economic activities is high. Activities that introduce high concentrations of these chemicals into the environment are still taking place. Majority of people are however not aware of the consequences of living with the presence of these chemicals in the environment. There is therefore the need for the appropriate policies to be put in place to control these activities in Nigeria (Eneh, 2011).

The production of PCBs has been banned globally, but significant quantities of these chemicals may still be available, especially in developing countries like Nigeria where the importation of second hand goods of all sorts are in place. Old computers, electronic devices, electrical and home appliances, among other goods are being brought into Nigeria on daily basis. Electronic wastes are openly burnt and dumped at uncontrolled locations all over the country and especially in Lagos which is the most populated city in Nigeria. As of 2015, unofficial figures put the population of "Greater Metropolitan Lagos", which includes Lagos and its surrounding metro area, extending as far as into Ogun State, at 21,324,000, which is more than $10 \%$ of the total population of $193,392,517$ and accounts for over $60 \%$ of the industrial and commercial activities in Nigeria (Metro Lagos, 2015). From the National population commission, the population of Lagos as of 2016 was estimated as 12,550,598, accounting for over $5 \%$ of the total population of $193,392,517$, based on the population census of 2006 conducted by the National population commission (NPC, 2015).

Presently OCs are still in use for the control of 
disease vectors, including mosquitoes and the ectoparasites that transmit typhus fever in Nigeria. There is a high tendency of these OCs being circulated by air masses as well as washed into the lagoon during rainy season via the drainage systems. OCs have been identified as endocrine disrupting substances, which makes the exposure to these substances quite unsafe.

Apart from being washed into the lagoon via runoffs and leaching, plants and animals can take up these PBTs directly from the contaminated soils (Larsen et al., 2002). In the investigation of the uptake of trace elements and PAHs by vegetables grown in soils contaminated by trace elements and PAHs, higher concentrations of these contaminants were found in vegetables grown in contaminated soils than those grown on uncontaminated soils (Larsen et al., 2002). Plants have been found to take up pollutants through different pathways such as root uptake (Edwards, 1988), thus entering the food chain. Human health may therefore be affected by the consumption of vegetables grown on soils contaminated by PBTs (Leeuwen and Vermeire, 2007).

Soil pollution may have detrimental health effects on humans not only through its effect on the hygienic quality of food and drinking water, but also through its effect on air quality, e.g. enriched pollutant contents in airborne particles originating from soil (Sezgin et al., 2003).

Presently monitoring and toxicity data on PBTs in Nigerian soils are not available, and so the extent of pollution in the country in general and Lagos in particular is unknown (Eneh, 2011). In the International Persistent Organic Pollutants (POPs) elimination project, the International Persistent Organic Pollutants Elimination Network (IPEP) in its awareness-raising on socioeconomic effects of persistent organic pollutants (POPs) in Nigeria in May 2006, stressed the need to take an inventory of all the sources of POPs in Nigeria, and also to generate a database on the current environmental levels of POPs in the country.

This research is necessary considering the paucity of information on the level of POPs in the Nigerian environment (Weiss et al., 1994). This work is therefore aimed at providing a baseline information on PBTs by monitoring the level of PBTs (polychlorinated biphenyls, organochlorine pesticides and polycyclic aromatic hydrocarbons) in Lagos soils and evaluating the soil environmental quality in terms of these pollutants.

\section{MATERIALS AND METHODS Sample Locations}

Table 1: Coordinates of the Sample Locations

\begin{tabular}{|c|c|}
\hline Locations & Coordinates \\
\hline Apapa 1 & $\mathrm{N6}^{\circ} 26^{\prime} 54.1464 ", \mathrm{E}^{\circ} 22^{\prime} 24.5688^{\prime \prime}$ \\
\hline Apapa 2 & $\mathrm{N6}^{\circ} 22^{\prime} 21.5698^{\prime \prime}, \mathrm{E} 3^{\circ}$ 22' 14.9556"” \\
\hline Apapa 3 & $\mathrm{~N} 6^{\circ} 27^{\prime} 6.7788^{\prime \prime N}, \mathrm{E}^{\circ}{ }^{2} 22^{\prime} 12.8568^{\prime \prime}$ \\
\hline Okobaba & N6²9’33.18”N, E3²3’21.714” \\
\hline Iddo & $\mathrm{N} 6^{\circ} 28^{\prime} 22.7994^{\prime \prime} \mathrm{N}, \mathrm{E}^{\circ} 22^{\prime} 59.5194 "$ \\
\hline
\end{tabular}

\section{Sampling and Sample Preparation}

Soil samples were collected from five locations in December, 2006. The samples were air-dried in aluminium wrapped trays for about a week, sieved through a $2 \mathrm{~mm}$ mesh screen, and packed in 100 $\mathrm{ml}$ amber glass bottles with aluminium sealed caps prior to soxhlet extraction. Sample preparation and analysis was carried using the procedure described by Lazar et al., (1992). Moisture and organic carbon contents of the soil samples were determined.

\section{Sample Analysis}

Sample extracts obtained after florisil cleanup were combined and rotoevaporated to $1 \mathrm{ml}$ and analyzed for Polycyclic Aromatic Hydrocarbons 
(PAHs), Polychlorinated Biphenyls (PCBs) and Organochlorine pesticides (OCs) by gas chromatography. Analysis was run on a HewlettPackard (Avondale, PA) Model 5890/5970 Gas Chromatograph with a mass selective detector (quadrupole mass analyzer, $70 \mathrm{eV}$ ) equipped with a Hewlett-Packard 7673A autosampler and a $30 \mathrm{~m} \mathrm{x}$ $0.25 \mathrm{~mm}$. I.D. X $0.10 \mu \mathrm{m}$ DB-5 film thickness column. $1 \mu \mathrm{l}$ sample was injected using a splitless injection mode at $250{ }^{\circ} \mathrm{C}$ injection temperature and GC-MSD interface temperature of $280^{\circ} \mathrm{C}$. A mixture of three ${ }^{13} \mathrm{C}$-labelled PCBs (13C - PCB 52, 13C - PCB 153 and 13C - PCB 37) was used as surrogate standard. The PAHs, PCBs, and OCs were identified and quantified by comparison of retention times and spectra of internal standards. The detection limit ranged between 0.02 to 0.06 $\mathrm{ng} / \mathrm{g}$ for organochlorine pesticides, between 0.03 to $0.11 \mathrm{ng} / \mathrm{g}$ for PCBs, and $0.02 \mathrm{ng} / \mathrm{g}$ for PAHs. Contaminants that were not detected were replaced with the detection limit value. Soil samples were analyzed for 16 PAHs, 72 PCBs, and 16 OCs and the results were expressed on dry weight basis.

\section{Results and Discussions \\ Soil Properties}

The properties investigated in the soil samples are shown in table 2.

Table 2: Moisture and Organic Carbon Contents of Soil Samples

\begin{tabular}{cccccc}
\hline & \multicolumn{5}{c}{ Sample locations } \\
\cline { 2 - 6 } Soil properties & Iddo & Okobaba & Apapa 1 & Apapa 2 & Apapa 3 \\
\hline Moisture content (\%) & 4.22 & 4.92 & 2.07 & 6.49 & 2.36 \\
Organic carbon (\%) & 39.39 & 24.95 & 0.47 & 4.97 & 0.92 \\
\hline
\end{tabular}

The least concentration of organic carbon was obtained in Apapa1 samples while the highest was obtained in Iddo samples. Moisture contents ranged between 2.07 and $6.49 \%$, with Apapa1 having the highest moisture content of $6.49 \%$, while Iddo and Okobaba had values of 4.22 and $4.92 \%$ respectively.

\section{Concentrations of PAHs in the Soil Samples}

The concentrations of individual PAHs obtained in the soil samples are shown in table 3. Sum total of polycyclic aromatic hydrocarbons (PAHs), which comprise $16 \mathrm{EPA}$ priority $\mathrm{PAHs}$, ranged between 30.92 to 2,706.93 ng/g. Highest PAH level was found in Iddo soil which may be as a result of high municipal activities (industrial, agricultural, municipal and domestic waste burning and disposal, and several other activities). At Iddo, only Anthracene, Benzo(k)fluoranthene, Benzo(b)fluoranthene, and Benzo(g,h,i)perylene were below the Dutch values for unpolluted soil. The values at Apapa were all below the Dutch values for unpolluted soil (Table 3), except for Phenanthrene, Fluoranthene and Chrysene at Apapa 2. Benzo(a)pyrene, a known carcinogen which has sufficient evidence of carcinogenicity in experimental animals according to the estimation of the International Agency for Research on Cancer (Manoli et al., 2000), was identified in all soil samples. Benzo (a) pyrene concentration in Okobaba soil $(59.59 \mathrm{ng} / \mathrm{g})$ was found to be above the threshold level of $25 \mathrm{ng} / \mathrm{g}$ (Table 3) set by Dutch government. 
Alani et al.: Assessment of Lagos Soils for Some Persistent Organic Pollutants

Table 3: Concentrations of PAHs in Soil Samples from Different Locations in Lagos in Dec., 2006

\begin{tabular}{lcccccc}
\hline \multirow{2}{*}{ Soil PAHs } & \multicolumn{5}{c}{ Concentrations $(\mathrm{ng} / \mathrm{g})$} & \multicolumn{2}{c}{ Dutch target } \\
\cline { 2 - 6 } & APAPA 1 & APAPA 2 & APAPA 3 & OKOBABA & IDDO & - \\
\hline NA & ND & 1.54 & 11.20 & 355.03 & 1625.10 & - \\
AL & 0.54 & 0.59 & ND & ND & 35.52 & - \\
AE & ND & 1.11 & 10.61 & ND & 45.43 & - \\
FL & 0.41 & 1.56 & 10.85 & 17.31 & 60.97 & 45 \\
PHE & 1.21 & 9.79 & 56.31 & 225.80 & 497.34 & ND \\
AN & 2.69 & 4.34 & 6.71 & 18.66 & 144.81 & 20 \\
FLT & 1.46 & 16.41 & 65.53 & 96.79 & 149.64 & - \\
PY & 4.59 & 24.18 & 61.14 & 79.47 & 23.42 & 20 \\
B(a)A & 0.59 & 7.68 & 18.89 & 32.74 & 75.49 & 20 \\
Chrysene & 5.30 & 7.69 & 20.12 & 76.76 & 21.02 & - \\
B(b)F & 1.77 & 10.42 & 20.93 & 47.79 & 16.56 & 25 \\
B(k)F & 1.08 & 6.74 & 14.63 & 37.29 & 3.70 & 25 \\
B(a)P & 7.39 & 13.70 & 9.02 & 59.59 & ND & 25 \\
IP & 1.49 & 5.59 & 10.80 & 39.97 & ND & - \\
D(ah)A & ND & ND & 1.87 & 5.39 & 7.93 & 20 \\
B(ghi)P & 2.42 & ND & 13.41 & 32.84 & & \\
\hline
\end{tabular}

Abbreviations: ND $=$ No Detection, Naphthalene-NA, Acenaphthylene - AL, Acenaphthene - AE, Fluorene - FL, Phenanthrene - PHE, Anthracene - AN, Fluoranthene - FLT, Pyrene - PY, Benzo(a)anthracene - B(a)A Benzo(b)fluoranthene - B(b)F, Benzo(k)fluoranthene - B(k)F, Benzo(a)pyrene - B(a)P, Indeno(1,2,3,cd)pyrene - IP, Dibenzo(ah)anthracene - D(ah)A, and Benzo(ghi)perylene - B(ghi)P.

The PAH levels in Lagos soils, at some locations such as Iddo (Table 3), are similar to levels found by Zohair et al., (2006) in soils from organic farms in England ranging from $590 \pm 43$ to $2301 \pm 146$ ng/g. Based on reported background PAHs concentrations of $2-22 \mathrm{ng} / \mathrm{g}$ in Bulgaria by (Attanassov et al., 2001) and suggested level of endogenous total PAHs concentrations of 1-10 $\mathrm{ng} / \mathrm{g}$ in soils (Edwards 1983), it could be concluded that Lagos soils are contaminated above the natural and background levels as majority of the values range above $10 \mathrm{ng} / \mathrm{g}$ (Table 2).

PAH concentrations in soils at Iddo, Okobaba and Apapa 3, ranging from 56.31 to $1625.10 \mathrm{ng} / \mathrm{g}$, compare well with the range of background PAHs levels of $89.5-4488 \mathrm{ng} / \mathrm{g}$ in soils in Italy as reported by Morillo et al., (2007), 100-1000 ng/g as reported by Minissi et al., (1998), $1000 \mathrm{ng} / \mathrm{g}$ in Czech Republic as reported by Sanka, (2001) and $370-770 \mathrm{ng} / \mathrm{g}$ for Krakow in Poland; 800-1,300 $\mathrm{ng} / \mathrm{g}$ and $80-1,640 \mathrm{ng} / \mathrm{g}$ in Japan as reported by Škrbix et al., (2005). Individual PAH concentrations (including $\mathrm{BaP}$ concentration of $59.59 \mathrm{ng} / \mathrm{g}$ ) at Okobaba were all above the target values set by Dutch government for unpolluted soil for almost all studied cases except for Anthracene. At Iddo only very few PAHs were found at levels lower than Dutch government target values.

\section{Concentrations of PCBs in the Soil Samples}

Soil samples were analysed for 72 PCBs but only 27 PCBs were found as shown in table 4. 
Alani et al.: Assessment of Lagos Soils for Some Persistent Organic Pollutants

Table 4: PCB Concentrations in Soil Samples from Different Locations in Lagos in Dec., 2006

\begin{tabular}{|c|c|c|c|c|c|}
\hline \multirow[t]{2}{*}{ Soil PCB } & \multicolumn{5}{|c|}{ Concentrations (ng/g) } \\
\hline & APAPA 1 & APAPA 2 & APAPA 3 & OKOBABA & IDDO \\
\hline PCB18 & ND & ND & ND & 0.39 & 0.72 \\
\hline PCB 16/32 & ND & ND & ND & 0.17 & 0.20 \\
\hline PCB $31 / 28$ & ND & ND & ND & 0.76 & ND \\
\hline PCB 33/20 & ND & ND & ND & 0.15 & ND \\
\hline PCB 52 & ND & ND & 0.36 & ND & ND \\
\hline PCB 49 & ND & ND & 0.65 & ND & 0.64 \\
\hline PCB 47/48 & ND & ND & 0.37 & ND & ND \\
\hline PCB 40 & ND & 2.31 & ND & ND & ND \\
\hline PCB 74 & 9.29 & 23.64 & 3.55 & 9.54 & 5.01 \\
\hline PCB 95 & ND & ND & 0.39 & 0.35 & 0.16 \\
\hline PCB 101 & ND & ND & 0.27 & ND & 0.24 \\
\hline PCB 99 & ND & ND & 0.39 & ND & ND \\
\hline PCB 110 & ND & ND & ND & 0.41 & ND \\
\hline PCB 105 & ND & ND & 0.85 & 4.04 & ND \\
\hline PCB 136 & ND & ND & ND & ND & 0.10 \\
\hline PCB149 & ND & 0.21 & 0.33 & 0.59 & 0.33 \\
\hline PCB 153 & ND & 0.12 & 0.61 & 0.92 & 0.48 \\
\hline PCB 138 & ND & ND & 0.24 & 0.77 & 0.43 \\
\hline PCB $187 / 182$ & ND & ND & 0.30 & ND & 0.24 \\
\hline PCB 183 & ND & ND & ND & ND & 0.07 \\
\hline PCB 185 & ND & ND & ND & ND & 1.16 \\
\hline PCB 174 & ND & ND & ND & ND & 0.26 \\
\hline PCB 177 & ND & ND & ND & ND & 0.11 \\
\hline PCB 171 & ND & ND & ND & ND & 0.46 \\
\hline PCB 180 & ND & ND & 0.60 & ND & 0.45 \\
\hline PCB 201 & ND & ND & 0.23 & ND & ND \\
\hline PCB 196/203 & ND & ND & 0.23 & ND & ND \\
\hline
\end{tabular}

Abbreviation: ND = No Detection

The PCB concentrations in Lagos soils which were between $0.07 \mathrm{ng} / \mathrm{g}$ of PCB 183 in Iddo soil to $9.54 \mathrm{ng} / \mathrm{g}$ of $\mathrm{PCB} 74$ in Okobaba. This compared well with the concentrations of PCBs in soils from organic farms in England which ranged from $3.56 \pm 0.73$ to $9.61 \pm 1.98 \mathrm{ng} / \mathrm{g}$ as reported by Zohair et al., (2006), except for 23.64 $\mathrm{ng} / \mathrm{g}$ of PCB 74 in Apapa 2 soil. Background PCB concentrations in various types of soil in Poland ranging between 2.3-38 ng/g (Falandysz et al., 1997), and $1 \mathrm{ng} / \mathrm{g}$ in Bulgaria (Atanassov et al., 2001) were very similar to the values obtained in Lagos soils. PCB concentrations were similar in many countries with exception of slightly higher values (0-134 ng/g) in Romania, and more

pronounced in Katowice town in Poland (67-870 ng/g) reported by Škrbix et al., (2005). The most abundant PCB, PCB 74, was present in all the samples. Only PCB $74(9.29 \mathrm{ng} / \mathrm{g})$ was found in Apapa 1 soil. According to the World Health Organization, Soil and sediments normally contain concentrations of PCBs in the range of $<0.01-2.0 \mathrm{ng} / \mathrm{g}$. In polluted areas, the levels in soils have been much higher, up to $500 \mathrm{ng} / \mathrm{g}$ (WHO, (1992). This shows that the soils examined in this study are polluted with PCBs as shown in table 4.

\section{Concentrations of Organochlorine Residues in the Soil Samples}

Lagos soil samples were investigated for 
organochlorine pesticides (OCs) based on the standard mixture of $16 \mathrm{OCs}$ and 15 of them were found as shown in table 5. No organochlorine pesticide was found in Apapa 3 soil, also deltahexachlorocyclohexane was not found in any of the soil samples evaluated.

Table 5: OCs Concentrations in Soil Samples from Different Locations in Lagos in Dec., 2006

\begin{tabular}{lccccc}
\hline \multirow{2}{*}{ Soil OCs } & \multicolumn{5}{c}{ Concentrations (ng/g) } \\
\cline { 2 - 6 } 1245-TCB & APAPA 1 & APAPA 2 & APAPA 3 & IDDO & OKOBABA \\
1234-TCB & ND & ND & ND & 1.09 & 2.18 \\
QCB & ND & ND & ND & 0.90 & 1.23 \\
HCB & ND & ND & ND & 1.07 & 1.40 \\
a-HCH & ND & ND & ND & 1.60 & 0.48 \\
b-HCH & ND & ND & ND & 4.15 & 1.01 \\
d-HCH & ND & ND & ND & 10.05 & ND \\
g-HCH & ND & ND & ND & ND & ND \\
trans-chlordane & 4.62 & ND & ND & ND & ND \\
cis-chlordane & 0.28 & ND & ND & ND & ND \\
trans-nonachlor & 0.29 & ND & ND & ND & ND \\
p,p'-DDE & 0.48 & ND & ND & ND & ND \\
p,p'-DDD & 4.66 & ND & ND & 2.33 & 117.98 \\
cis-nonachlor & ND & ND & ND & 0.98 & 63.61 \\
p,p'-DDT & 0.13 & ND & ND & ND & ND \\
Mirex & ND & ND & ND & 29.56 & 33.22 \\
\hline
\end{tabular}

Abbreviations: $\mathrm{ND}=\mathrm{No}$ detection, 1245 tetrachlorobenzene - 1245-TCB, 1234 tetrachlorobenzene - 1234-TCB, pentachlorobenzene - QCB, alpha hexachlorocyclohexane - a$\mathbf{H C H}$, beta hexachlorocyclohexane - b-HCH, delta hexachlorocyclohexane - d-HCH, gamma hexachlorocyclohexane - g-HCH, 1,1-Dichloro-2,2-bis(p-chlorophenyl)ethane - p,p'-DDE, 1,1Dichloro-2,2-bis(4-chlorophenyl)ethane - p,p'-DDD, 1,1'-(2,2,2-trichloroethylidene)-bis(4-chlorobenzene) - p,p'-DDT

The concentrations of OCs in Lagos soils which ranged from $0.13-117.98 \mathrm{ng} / \mathrm{g}$ were in some cases below and in some cases within the range $(52.2 \pm 4.9$ to $478 \pm 111 \mathrm{ng} / \mathrm{g})$ obtained in soils from organic farms in England by Zohair et al., (2006). Among the organochlorine pesticides, 1,1Dichloro-2,2-bis(p-chlorophenyl)ethane, 1,1Dichloro-2,2-bis(4-chlorophenyl)ethane and 1,1'(2,2,2-trichloroethylidene)-bis(4-chloro-benzene) predominated with concentrations of 118.00 , 63.61, and 33.22ng/g respectively in Lagos soils. Apart from the DDTs, $\beta-\mathrm{HCH}$ predominated with the concentration of $10.05 \mathrm{ng} / \mathrm{g}$. This was similar to the report by Zhang et al., (2005) that among the OCs and their homologues or isomers analysed in Hong Kong soils, $\beta-\mathrm{HCH}$ and $p, p^{\prime}-$ DDE were the two predominant substances according to the concentrations and detectable ratios, though the concentrations in Lagos soils were higher than the values ( 6.12 and $0.41 \mathrm{ng} / \mathrm{g}$ for $\beta$-HCH and $p, p^{\prime}$-DDE respectively) in soils from that report. Two $\mathrm{HCH}$ isomers were found in Lagos soils. Gamma-HCH (lindane) was found in only the samples from Apapa $1(4.62 \mathrm{ng} / \mathrm{g})$ while $\beta-\mathrm{HCH}$ was found also in one sample from Okobaba (10.05 ng/g). Lindane in Lagos soil was present within the level $(1.54-5.60 \mathrm{ng} / \mathrm{g})$ observed by Manz et al., (2001) in agricultural soils in central Germany, and much higher than the level (0.9 $\mathrm{ng} / \mathrm{g}$ ) reported by Holoubek et al., (1999) for Slovak Republic.

Concentrations of $\mathrm{p}, \mathrm{p}^{\prime}$-DDT in Lagos soils were above the range $(1.0-5.1 \mathrm{ng} / \mathrm{g})$ reported in some 
European countries by Holoubek et al., (1999) for Czech Republic and 0.26-17.86ng/g by Škrbix et al., (2005) for Novi Sad, but were within the range (2.83-423.60 ng/g) reported by Shegunova et al., (2001) for Bulgaria. Concentration of p,p'-DDE was highest $(117.98 \mathrm{ng} / \mathrm{g})$ at Iddo, a location with very high municipal and agricultural activities.

At location A (Iddo), p,p'DDT was the highest in concentration $(29.56 \mathrm{ng} / \mathrm{g})$, followed by b-HCH (10.05 ng/g). At B3 (Okobaba), the DDTs were very high in concentration (p,p'DDE, 117.98 ng/g; p,p'DDD, $63.61 \mathrm{ng} / \mathrm{g}$; and p,p'DDT, 33.22 $\mathrm{ng} / \mathrm{g}$ ) compared to other OCs (ranging between $0.48 \mathrm{ng} / \mathrm{g}$ of HCB to $2.18 \mathrm{ng} / \mathrm{g}$ of $1245-\mathrm{TCB})$. Okobaba sample site is actually a slum settlement by the lagoon front, where mosquito breeding rate could be very high. The key factor responsible for p,p'DDT concentration is the pattern of use (Mackay et al., 1997).

\section{Total Persistent Organic Pollutants in the} Soil Samples

The results from this study showed that PBT contamination of Lagos soils vary with locations. Table 6 showed that PAHs were the most abundant of the contaminants assessed in Lagos soils, with Iddo soil having the highest sum of PAHs of $2706.93 \mathrm{ng} / \mathrm{g}$. Of all the locations assessed in this study, Iddo is the one with highest municipal activities. This result was thus similar to the report by Van metre et al., (2000), that the largest concentrations of PAHs generally are found in urbanized areas, where the potential sources include atmospheric deposition, surface runoff, municipal wastes, sewage effluents, industrial effluents, and spills and leakage of fossil fuels. It was also noticed that Iddo soil also had the highest percent organic carbon of 39.39\%.

Table 6: Total Persistent Organic Pollutants (ng/g, Dry Weight Sample) in Soils from Different Locations

\begin{tabular}{lcccc}
\hline Locations & \multicolumn{3}{c}{ Concentrations $(\mathrm{ng} / \mathrm{g})$} & Organic carbon \\
\cline { 2 - 4 } & PAHs & PCBs & OCs & $(\%)$ \\
\hline Iddo & 2706.93 & 11.02 & 51.73 & 39.39 \\
Okobaba & 1125.00 & 18.08 & 221.11 & 24.95 \\
Apapa 1 & 30.92 & 9.29 & 10.47 & 0.47 \\
Apapa 2 & 111.30 & 26.27 & 0.59 & 4.97 \\
Apapa 3 & 332.00 & 9.35 & 0.00 & 0.92 \\
\hline
\end{tabular}

Sum PAHs content in some locations in Lagos (Iddo and Okobaba) were above (2706.93 $1125.00 \mathrm{ng} / \mathrm{g}$ ), and in some cases (Apapa soils) lower $(30.92-332.00 \mathrm{ng} / \mathrm{g})$ than the values of the ones determined for the agricultural soils of Czech Republic (693-1,067 ng/g) by Škrbiæ et al., (2005), and Slovakia (204-1,093 ng/g) by Linkeš etal., (1997).

Sum PAHs of $1,125.00 \mathrm{ng} / \mathrm{g}$ was found at Okobaba, and this could be as a result of the incessant burning of saw dust at this location. Sum PAHs at Iddo was 8 to 90 fold higher than the values at Apapa locations, which are mainly influenced by oil related activities. Also sum PAHs at Okobaba was 3 to 24 fold higher than those of
Apapa locations. Sum PAH determined in Lagos soils were much lower that the intervention value for soil sanitation (40,000 ng PAHs/g) used by the Dutch government (VROM, 1994, Van Brummelen etal., 1996).

Sum PCBs (27 PCBs found) determined in Lagos soil which ranged from 9.29 to $26.27 \mathrm{ng} / \mathrm{g}$ were far above (30 to 114 times) the range of values $(0.36$ and $0.23 \mathrm{ng} / \mathrm{g}$ ) obtained in Novi Sad as reported by Sanka, (2001).

Considering that the limit value for the sum OCs is $0.1 \mathrm{mg} / \mathrm{kg}$ (100 ng/g), according to Slovenian regulation (Zupan etal., 2001), the contents of the ones determined at most of the investigated sites 
in Lagos (except Okobaba) did not exceed the value of $0.1 \mathrm{mg} / \mathrm{kg}$ and therefore they could not be a threat to the environment at these locations.
At Okobaba, sum OCs was $221.11 \mathrm{ng} / \mathrm{g}$, which doubled the limit value, and so, there is a serious threat of OCs at Okobaba in Lagos.

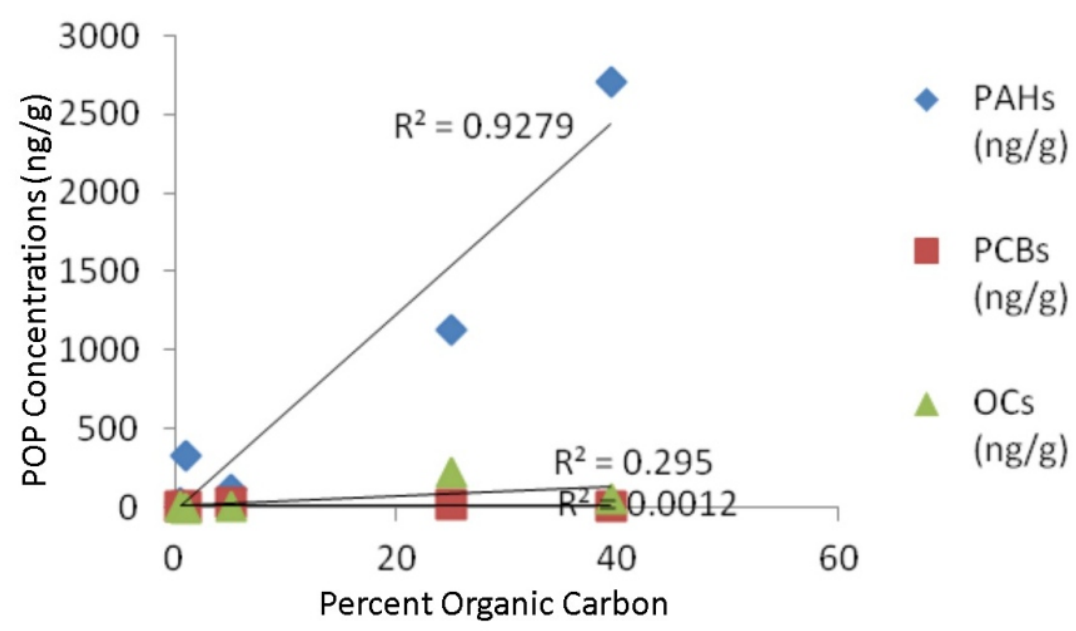

Figure 1: Correlation of Organic Carbon with Persistent Organic Compounds in Lagos Soils

Sum PAHs was least at Apapa $1(30.92 \mathrm{ng} / \mathrm{g})$ and the percent organic carbon content was also least at this location $(0.47 \%)$. As indicated in table 2 and figure 1 , positive correlation between percent organic carbon contents and contaminant concentration was mostly reflected in the PAHs. This is similar to the report by Smith et al., (1988) that PAHs and other nonpolar organic compounds are strongly associated with the organic fraction.

As shown in table 6, Iddo which had the highest $\mathrm{PAH}$ concentration leveled up with the other locations, while Apapa 3 which had low PAH concentration became the most contaminated with PAHs. Other PBTs also leveled up on organic carbon normalization, especially at Apapa 1 location. With organic carbon normalization, Apapa 2 was seen as the most contaminated location with PAHs and PCBs while Okobaba remained the most contaminated location with OCs.

\section{CONCLUSION}

The highest total content of PAHs $(2706.93 \mathrm{ng} / \mathrm{g})$ in the soil samples analyzed was found in the Iddo soil where high commercial activities was observed. Also based on the values of identified PAHs components, it could be concluded that they were above the suggested level of endogenous total PAHs concentrations in soils, and also above the target values set by Dutch government in almost all studied cases, including $\mathrm{BaP}$. The high PCB levels in these soil samples further gives credence to the urgent attention required to avoid a potential environmental and human health disaster. Comparing OCs contents from literature data from England, Poland, Czech Republic, Slovak Republic, Bulgaria, Germany, Hong Kong and Serbia which were used as standards shows that Lagos soils are polluted with OCs. Since the OCs at Okobaba doubled the limit value according to Slovenian regulation, it could be concluded that there is a serious threat of soil pollution by OCs at some locations in Lagos.

\section{REFERENCES}

Atanassov, I., Terytze, K. and Atanassov, A. (2001). Background values for heavy metals, PAHs and PCBs in the soil of Bulgaria. In: assessment of the quality of contaminated soils and sites in central and eastern European countries (CEEC) and New Independent States (NIS), Terytze K, Atanassov I (Eds), Proceeding of International Workshop, Sofia, Bulgaria, 83-108.

Edwards, N. T. J. (1983). Polycyclic aromatic hydrocarbons (PAHs) in the terrestrial environment - A review. Journal of 
Environmental Quality, 12: 427-441.

Edwards, N. T. (1988). Assimilation and metabolism of polycyclic aromatic hydrocarbons by vegetation. An approach to this controversial issue and suggestions for future research. In: Polycyclic aromatic hydrocarbons: A decade of progress. Cook, M. and Dennis, A. J. (Eds.) 10th International Symposium Battlle Press. Columbus, OH. 211 - 299.

Eneh, O.C., 2011. Failed development vision, political leadership and Nigeria's underdevelopment: A critique. Asian Journal of RuralDevelopment, 1: 63-69

Falandysz, J., Kawano, M. and Wakimoto, T. (1997). Polichlorinated biphenyls (PCBs) contamination of soil in a former army base in Poland. Organobalen Compounds, 42: 172-177.

Holoubek, I., Kocan, A., Holoubkova, I., Kohoutek, J. and Falandysz, J. (1999). Persistent, bioaccumulative and toxic chemicals in central and eastern European countries - State-of-the-art report. Environmental Science and Pollution Research, 6: (3) 183-183.

Metro Lagos (Nigeria): Local Government Areas". City Population. 21 March 2015.

Lazar, R., Edwards, R. C., Metcalfe, C. D., Metcalfe, T., Gobas, F. A. P. C. and Haffner, G. D. (1992). A simple, novel method for the quantitative Analysis of coplanar (non-ortho substituted) polychlorinated biphenyls in environmental samples. Chemosphere, 25: 493-504.

Larsen, E. H., Samse-Petersen, L., Larsen, P. B. and Bruun, P. (2002). Uptake of trace elements and PAHs by fruit and vegetables from contaminated soils. Environmental Science and Technology, 36: (14) 3057-3063

Van Leeuwen, C.J. and Vermeire, T. G. (2007). Risk assessment of Chemicals. An Introduction. The Netherlands, Springer. $1-621$

Linkeš, V., Kobza, J., Švec, M., Ilka, P., Pavlenda, P., Baranèikova, G. and Matuškova, L. (1997). Soil Monitoring of Slovak Republic, Present State of Monitored Soil
Properties. The Results of Partial Monitoring System-Soil as a Part of Environment Monitoring of Slovak Republic for the Period 1992/96.; Soil Fertility Research Institute (VUPU): Bratislava, Slovak Republic.

Mackay, D., Shiu, W. Y. and Ma, K. C. (1997). Illustrated Handbook of Physical Chemical Properties and Environmental Fate for Organic Chemicals, Vol. V. Pesticide Chemicals. Lewis Publishers/CRCPress, New York, NY.

Manoli, E., Samara, C., Konstantinou, I. and Albanis, T. (2000). Polycyclic aromatic hydrocarbons in the bulk precipitation and surface waters of Northern Greece. Chemosphere, 41:1845-1855.

Manz, M., Wenzel, K. D., Dietze, U. and Schuurmann, G. (2001). Persistent organic pollutants in agricultural soils of central Germany. Science of the Total Environment, 277:187-198.

Minissi, S., Caccese, D., Passafiume, F., Grella, A., Ciccotti, E. and Rizzoni, M. (1998). Mutagenicity (micronuclear test in Vicia faba root tips), polycyclic aromatic hydrocarbons and heavy metal content of sediment collected in Tiber river and its tributaries within the urban area of Rome. Mutation Research, 420: 77-84.

Morillo, G. E., Romero, A. S., Maqueda, P. C., Madrid, L., Ajmone-Marsan, F., Grcman, H., Davidson, C. M., Hursthouse, A. S. and Villaverde, C. J. (2007). Soil pollution by PAHs in urban soils: a comparison of three European cities. Journal of Environmental Monitoring, 9: 1001 1008.

NPC (National Population Commission of Nigeria). (2015). Lagos Bureau of Statistics. https://www.citypopulation. $\mathrm{de} / \mathrm{php} /$ nigeria-metrolagos.php

Sanka, M. (2001). Program of soil monitoring and register of contaminated sites in the Czech Republic: Their role as database sources in state administration and for setting the limit values in soil. In: Assessment of the Quality of Contaminated Soils and Sites in Central and Eastern European Countries 
(CEEC) and New Independent States (NIS), Terytze, K. and Atanassov, I. (Eds). Proceeding of International Workshop, Sofia, Bulgaria, 33-36.

Sezgin, N., Kurtulus, H., Demir, G., Nemlioglu, S. and Bayat, C. (2003). Determination of heavy metal concentrations in street dust in Istanbul E-5 highway. Environment International, 29:979-985.

Shegunova, P., Terytze, K. and Atanassov, I. (2001). Priority organic pollutants in soils of Bulgaria. In: Assessment of the Quality of Contaminated Soils and Sites in Central and Eastern European Countries (CEEC) and New Independent States (NIS). Terytze, K. and Atanassov, I., (Eds). Proceeding of International Workshop, Sofia, Bulgaria, 30 September-3 October, 202-209.

Škrbiæ, B., Cvejanov, J., and DjurišiæMladenoviæ, N. (2005). Some Toxic Substances in Surface Soil in Novi Sad Area. Faculty of Technology, Bulevar cara Lazara 1, 21000 Novi Sad Serbia, 110.

Smith, J. A., Witkowski, P. J., and Fusillo, T. V. (1988). Manmade organic compounds in the surface waters of the United States-A review of current understanding: U.S. Geological Survey Circular 1007, 92.

Van Brummelen, T. C., Verweij, S. A. and Van Gestel, C. A. M. (1996). Enrichment of polycyclic aromatic hydrocarbons in forest soils near a blast furnace plant. Chemosphere, 32: 293-314.

Van metre, P. C., Manler, B. J. and Furlong, E. T. (2000). Urban Sprawl Leaves its PAH
Signature. Environmental Science and Technology, 34: 4064-4070.

VROM (1994). Environmental Quality Objectives in the Netherlands. A review of Environmental Quality Objectives and the Policy Framework in the Netherlands. Dutch Ministry of Housing. Spatial Planning and the Environment.

Weiss, P., Riss, A., Gschmeidler, E. and Schentz, H. (1994). Investigation of heavy metal, $\mathrm{PAH}, \mathrm{PCB}$ patterns and PCDD/F profiles of soil samples from an industrial urban area (Linz, upper Austria) with multivariate statistical methods. Chemosphere. 29: 2223-2236.

WHO (World Health Organisation) (1992). Environmental Health Criteria 140; Polychlorinated biphenyls and terphenyls (Second Edition).

Zhang, H. B., Luo, Y. M., Zhao, Q. G., Wong, M. H. and Zhang, G. L. (2005). Residues of organochlorine pesticides in Hong Kong soils. Chemosphere 63(4):633-41

Zohair, A., Salim, A. B., Soyibo, A. A. and Beck, A. J. (2006). Residues of polycyclic aromatic hydrocarbons (PAHs), polychlorinated biphenyls (PCBs) and organochlorine pesticides in organically-farmed vegetables. Chemosphere, 63 (4), 541-553.

Zupan, M., Turk, I., Lobnik and F. (2001). Soil pollution assessment in Slovenia. In: Assessment of the Quality of Contaminated Soils and Sites in Central and Eastern European Countries (CEEC) and New Independent States (NIS). Terytze, K., Atanassov, I. (Eds.). Proceedings of International Workshop, Sofia, Bulgaria, 79-82. 